\title{
Molecular Simulation of Displacement of Shale Gas by Carbon Dioxide at
}

\section{Different Geological Depths}

\author{
Haibo Zhang ${ }^{1}$ and Dapeng Cao ${ }^{* 1,2}$ \\ ${ }^{1}$ State Key Lab of Organic Inorganic Composites, Beijing University of Chemical \\ Technology, Beijing 100029, P. R. China \\ ${ }^{2}$ International Research Center for Soft Matter, Beijing University of Chemical Technology, \\ Beijing 100029, P. R. China
}

\begin{abstract}
The rising worldwide energy demand has greatly stimulated the exploitation of shale gas. Meantime, global warming mainly caused by $\mathrm{CO}_{2}$ emission is a significant concern. As a new scenario, injecting $\mathrm{CO}_{2}$ to displace shale gas is proposed to improve the exploitation efficiency of shale gas and reduce the amount of $\mathrm{CO}_{2}$ emission. In this work, we use a grand canonical Monte Carlo simulation to investigate the displacement of shale gas by $\mathrm{CO}_{2}$ and the sequestration of $\mathrm{CO}_{2}$ simultaneously in a modeled shale matrix at different geological depths from 1 to $4 \mathrm{~km}$, where the shale is modeled by inorganic clay mineral and organic matter. We find that both the displacement amount of $\mathrm{CH}_{4}$ and the sequestration amount of $\mathrm{CO}_{2}$ increase with the pore size of the shale at a fixed $\mathrm{CO}_{2}$ injection pressure, which suggests that the hydro-fracturing technology would be very beneficial for displacement exploitation of shale gas. Moreover, we also find that the optimum operating condition for $\mathrm{CO}_{2}$ displacing shale gas is at the depth of $1 \mathrm{~km}$, which provides a guidance and reference for displacement exploitation of shale gas by $\mathrm{CO}_{2}$.
\end{abstract}

* Corresponding Authors. Email: caodp@,mail.buct.edu.cn 


\section{INTRODUCTION}

Recently, the exploration and development of shale gas have received extensive attention worldwide because of its numerous advantages such as low pollution, wide distribution, and abundant resource (Howarth et al., 2011). Shale gas, as an unconventional gas source, refers to a kind of natural gas that exists in shale reservoirs (Shaikh and Ji, 2016; Youinou, 2016), and is now increasingly deemed as a low carbon and an environmentally friendly energy option. The United States of America (USA) is the earliest country to apply the horizontal drilling and hydro-fracturing into the exploration and development of shale gas (Arora and Cai, 2014; Connor et al., 2015). The output of shale gas has reached 13.78 billion cubic meters per year in USA, with an average annual growth rate of $47.7 \%$ (Zhai et al., 2014), while, the natural gas from shale formations is about $23 \%$ in 2010 . And, it is anticipated to contribute $49 \%$ of gas production by 2035 (Ashmoore et al., 2016). In order to reduce pollution and meet a surge in energy demand, China aims to produce 30 billion cubic meters of shale gas per year by 2020 , from the current level of 1.3 billion cubic meters(Wang et al., 2016). Therefore, considerable efforts are undertaken by Chinese enterprises through the development of research programs in industry to make this resource successfully and economically available (Gasparik et al., 2012).

Currently, the ultralow porosity of shale and ultralow permeability of gas reservoirs are still a great challenge in the exploration of shale gas (Clarkson et al., 2016). Hydro-fracturing is a commonly used method to enhance matrix permeability of unconventional reservoirs and enable the economic production of shale gas from the shale reservoirs (Chen and Carter, 2016; Clark et al., 2012; Clarkson et al., 2016). However, the 
hydro-fracturing would cause severe environment impacts, e.g. huge water consumption, potential contamination of water and so on(Clark et al., 2012; Connor et al., 2015; Krogulec and Sawicka, 2015; Krupnick and Gordon, 2015). Alternatively, the new scenario, the injection of $\mathrm{CO}_{2}$ gas to displace the adsorbed $\mathrm{CH}_{4}$, has been proposed by some researchers (Kowalczyk et al., 2012; Shi and Durucan, 2003; Wang et al., 2015b; Wu et al., 2015; Yu et al., 2008). It arouses extensive interests from scientists, because it can improve the shale gas recovery and sequestrate $\mathrm{CO}_{2}$ simultaneously.

Most studies on the displacement of $\mathrm{CH}_{4}$ adsorbed in shale matrix by $\mathrm{CO}_{2}$ have been carried out by the experiment and computation at present. Wu (Wu et al., 2015) studied the displacement of $\mathrm{CH}_{4}$ in carbon nanochannels by molecular dynamics (MD) simulations. And they drew a conclusion that $\mathrm{CO}_{2}$ can displace the adsorbed $\mathrm{CH}_{4}$ directly. Yuan(Yuan et al., 2015) also explored the displacement of $\mathrm{CH}_{4}$ by injecting $\mathrm{CO}_{2}$ on graphene, and found that $\mathrm{CO}_{2}$ can be adsorbed on graphene more easily than $\mathrm{CH}_{4}$, which may be a good candidate for displacement of $\mathrm{CH}_{4}$. Pathak (Pathak et al., 2015) performed MD simulations on the kerogen-methane-carbon dioxide system to understand the absorption- adsorptiondesorption phenomena of the super critical $\mathrm{CO}_{2}$ fluid, and found that $\mathrm{CO}_{2}$ can sweep the absorbed $\mathrm{CH}_{4}$ from the kerogen matrix in the shales. Kowalczyk (Kowalczyk et al., 2012) investigated displacement of $\mathrm{CH}_{4}$ by Monte Carlo simulations, and proposed two-stage mechanism for the displacement of $\mathrm{CH}_{4}$ from carbon nanospaces by coadsorbed $\mathrm{CO}_{2}$. Wang (Wang et al., 2015a) conducted experiments to study the coal-bed $\mathrm{CH}_{4}$ displacement by $\mathrm{CO}_{2}$ injection, and found that the adsorption capacity of $\mathrm{CO}_{2}$ is stronger than that of $\mathrm{CH}_{4}$ under the same condition in the process of displacement. 
A large proportion of pores within the gas shale matrix are nanosized, and most of these pores are associated with the constituents of the shale matrix and the contents of each components (Cui et al., 2009). In addition, the shale matrix often contains some free gases in relatively large pores and adsorbed gas on the organic matter and inorganic minerals(Zhang et al., 2012). To deal with the complex situation, it is necessary to simplify the complicated structure of shale matrix to gain some basic insights into its adsorption behavior. There are two ways to address this topic in the literatures. One is to assume the clay-rich shale as the crystal structure of montmorillonite with the basal spacing and number of ions changing (Zhai et al., 2014). The disadvantage of this method does not include the organic matter. In fact, the organic matter is an indispensable factor on the $\mathrm{CH}_{4}$ adsorption in shale matrix. The other method is to model the complex natural matrixes as a collection of independent, on-interconnected slit pores with perfect graphitic walls without consideration of inorganic minerals(Hu et al., 2011). As a result, it is important to construct an all-atom shale model including inorganic minerals and organic matter to investigate the adsorption and displacement of $\mathrm{CH}_{4}$ in gas shale matrix.

In this work, we proposed a modified and generalized shale matrix model including inorganic minerals and organic matter. Then, the mechanism of the displacement of $\mathrm{CH}_{4}$ by $\mathrm{CO}_{2}$ in shale matrix model was investigated through molecular simulations. Finally, some discussion was also addressed.

\section{Computational details}

\subsection{Models and potentials}

Since $\mathrm{CH}_{4}$ is the major component of shale gas, we use it to represent the shale gas. The 
components of gas shale matrix include organic matter, inorganic clay minerals, quartz, carbonate, calcite, pyrite, and the others (Tan et al., 2014). The main ingredients in the gas shale matrix from different places are nearly the same, but their contents of the components are different. Here, we mainly consider the case of $\mathrm{CH}_{4}$ in shale matrix, which contains organic matter and inorganic clay minerals. To construct the shale matrix model containing inorganic clay mineral and organic matter, we used two perfect montmorillonite sheets to represent the inorganic clay mineral. Montmorillonite is a typical 2:1 inorganic clay mineral, and the unit cell consists of an $\mathrm{Al}-\mathrm{O}$ octahedral sheet and two $\mathrm{Si}-\mathrm{O}$ tetrahedral sheets, while the $\mathrm{Al}-\mathrm{O}$ sheet is sandwiched between $\mathrm{Si}-\mathrm{O}$ sheets. Generally, it is believed that the polycyclic aromatic hydrocarbon is a major organic component of shale matrix, especially for shale gas reservoirs. Therefore, we used methylnaphthalene to represent the organic matter in the shale matrix here.

We constructed a simulation box $(31.1 \times 35.9 \times \mathrm{c} \AA)$ that contains two inorganic layers and two organic layers (see Figure 1). As mentioned above, the perfect montmorillonite sheets were used to represent the inorganic layers. The structure of the montmorillonite sheets was obtained from the Cambridge Crystallographic Data Centre (CCDC) database. First, two perfect montmorillonite sheets were stacked each other in such a way as shown in Figure 1. Then, a set of methylnaphthalene molecules were absorbed into the interlayer space, where the pore size of our model was adjustable through the basal spacing. The methylnaphthalene molecules absorbed into the interlayer space were fixed, as the organic matter in shale matrix. During our simulations, the shale matrix model containing organic and inorganic matter was treated as a rigid material with atoms frozen. 
In this work, $\mathrm{CH}_{4}$ was represented by a spherical united-atom model (Cao et al., 2003; Lan et al., 2010), $\mathrm{CO}_{2}$ was modeled as a three-site rigid linear molecule with three charged Lennard-Jones (LJ) interaction sites (Liu and Wilcox, 2013). The potential parameters were taken from the transferable potentials for phase equilibrium (TraPPE) model (Jorgensen et al., 1996). The realistic CLAYFF force field (Cygan et al., 2004) for inorganic clay minerals in the shale matrix model was used in this work, and the Dreiding force field(Mayo et al., 1990) was adopted for the organic matter in the shale matrix model. The site-site LJ potentials were adopted to calculate the $\mathrm{CH}_{4}-\mathrm{CH}_{4}$ and $\mathrm{CH}_{4}$-shale intermolecular interactions. In addition, when calculating the $\mathrm{CO}_{2}-\mathrm{CO}_{2}$ and $\mathrm{CO}_{2}$-shale intermolecular interactions, the Coulombic potentials were added. In the MUSIC software, to avoid the conversion of chemical potential into pressure, the normal move acceptance probability was transformed to relate with the component fugacity of gas bulk phase, which was calculated by the Peng-Robinson equation of state (EOS) (Peng et al., 2011). All the Lennard-Jones (LJ) cross-interaction parameters were determined by the Lorentz-Berthelot mixing rules $\left[\sigma_{\mathrm{ij}}=\left(\sigma_{\mathrm{ii}}+\sigma_{\mathrm{jj}}\right) / 2\right.$ and $\left.\varepsilon_{\mathrm{ij}}=\left(\varepsilon_{\mathrm{ii}} \cdot \varepsilon_{\mathrm{jj}}\right)^{1 / 2}\right]$, where corresponding parameters are shown in Table1.

\subsection{Grand canonical Monte Carlo simulations}

The grand canonical Monte Carlo (GCMC) simulations were used to investigate the displacement of $\mathrm{CH}_{4}$ in shale matrix at different geological depths. First, the $\mathrm{CH}_{4}$ molecules were preadsorbed into the nanochannels of the shale matrix. The partial pressure of $\mathrm{CH}_{4}$ in the binary $\mathrm{CH}_{4}-\mathrm{CO}_{2}$ bulk mixture, which is corresponding to the geological pressure condition of shale gas, determines the preadsorption amount of $\mathrm{CH}_{4}$ in the shale matrix. Then, we injected a small amount of $\mathrm{CO}_{2}$ molecules into the bulk $\mathrm{CH}_{4}$ gas and equilibrated 
the resulting mixture in the shale reservoirs. After equilibration, the adsorption amounts of $\mathrm{CO}_{2}$ and $\mathrm{CH}_{4}$ in shale matrix were calculated by analyzing the compositions of the adsorbed mixture. Finally, we gradually increased the $\mathrm{CO}_{2}$ partial pressure (i.e. $\mathrm{CO}_{2}$ injection pressure) in the binary $\mathrm{CH}_{4}-\mathrm{CO}_{2}$ bulk mixture up to $90 \mathrm{MPa}$, which makes it possible to study the microscopic mechanism of the displacement of $\mathrm{CH}_{4}$ from the shale matrix. In each case, $2 \times 10^{7}$ configurations were generated. The first half is for the system to reach the equilibrium, whereas the second half is for sampling.

In the displacement process of $\mathrm{CH}_{4}$ by $\mathrm{CO}_{2}$, the displacement amount of $\mathrm{CH}_{4}$ is defined as

$$
N_{\text {displacement }}=N_{\text {initial }}-N_{P_{\mathrm{CO}_{2}}}
$$

The percentage of displacement is defined as

$$
\eta_{\text {displacement }}=\frac{N_{\text {initial }}-N_{P_{\mathrm{CO}_{2}}}}{N_{\text {initial }}}
$$

Where $N_{\text {initial }}$ and $N_{P_{\mathrm{CO}_{2}}}$ denote absolute amount of $\mathrm{CH}_{4}$ adsorbed in the nanochannel of shale matrix when the partial pressure of $\mathrm{CO}_{2}$ in bulk mixture is equal to zero (i.e. pure $\mathrm{CH}_{4}$ ) and $P_{\mathrm{CO}_{2}}$, respectively.

The pore volume of the adsorbent accessible to the gas molecule is calculated by the method of Myers from the ideal gas law(Talu and Myers, 2001)

$$
V_{\text {pore }}=\frac{R N_{m} T}{p m_{m}}
$$

where $\mathrm{R}$ is the gas constant, $\mathrm{T}$ is the temperature, $p$ is the pressure, and $N_{m}$ is the number of adsorbed probe molecules per molar mass of the adsorbents, which is obtained from the GCMC simulations of non-adsorbed helium $\left(\varepsilon_{\mathrm{He}} / K_{\mathrm{b}}=10.22 \mathrm{~K} ; \sigma_{\mathrm{He}}=2.85 \AA\right)$ gas in shales at low pressure and ambient temperature. 
The temperatures and pressures corresponding to the specific geological depths were introduced in the simulations to reproduce the $\mathrm{T} / \mathrm{P}$ conditions encountered in a typical sedimentary basin, mainly based on the fact that the compacting stress gradient is 15 $\mathrm{MPa} / \mathrm{km}$ and the geothermal gradient is $30 \mathrm{~K} / \mathrm{km}$ (Cygan et al., 2004; Titiloye and Skipper, 2005). The T/P conditions were listed in Table 2. All the GCMC simulations were performed by using the computational packages MUSIC(Gupta et al., 2003).

\section{RESULTS AND DISCUSSION}

\subsection{Modeling.}

The total organic content and basal spacing of the shale matrix model were determined by fitting the experimental and simulation data. To validate the simulated data and the model, we made a series of comparisons with available experimental data from the literature. An experimental adsorption isotherm of $\mathrm{CH}_{4}$ in the shale with the total organic content of $5.08 \%$, was measured at $363 \mathrm{~K}$ by Zeng et al(Zeng et al., 2014). In agreement of the total organic content of shale matrix with the experimental sample, fourteen methylnaphthalene molecules were absorbed into the slit pore formed by two perfect montmorillonite sheets. Then, a series of adsorption isotherms of $\mathrm{CH}_{4}$ in the shale model with different basal spacing were simulated at $363 \mathrm{~K}$. By comparing the GCMC simulated isotherms and experimental one (see Figure 2), we could determine the basal spacing about $7 \AA$ for the shale model. The simulated pore volume of our shale model is $0.0173 \mathrm{~cm}^{3} / \mathrm{g}$, which is consistent with the experimental result of $0.0162-0.0448 \mathrm{~cm}^{3} / \mathrm{g}($ Clarkson et al., 2013). So, we believe that the shale model proposed here is rational, and further use the model to investigate the displacement of $\mathrm{CH}_{4}$ by $\mathrm{CO}_{2}$ in the shale matrix. 


\subsection{The Displacement of Shale Gas by Carbon Dioxide at Different Basal Spacings}

First, we used GCMC simulations to investigate the displacement of $\mathrm{CH}_{4}$ by $\mathrm{CO}_{2}$ in the shale at geological depth of $1 \mathrm{~km}$, in which the partial pressure of $\mathrm{CH}_{4}$ and the temperature are $15 \mathrm{MPa}$ and $310 \mathrm{~K}$, respectively, corresponding to the condition of the shale gas at the geological depth of $1 \mathrm{~km}$ (i.e. Case 1 in Table 2). Then, we injected $\mathrm{CO}_{2}$ into the shale, and the $\mathrm{CO}_{2}$ injection pressure is increased from 0 to $90 \mathrm{MPa}$. After equalization, the composition of the adsorbed mixture is further recorded and analyzed.

To explore the effect of pore size on the displacement of $\mathrm{CH}_{4}$ by $\mathrm{CO}_{2}$ in shale, we explored a series of modeled shales with different basal spacings. Figure $3 \mathrm{a}$ and $3 \mathrm{~b}$ show the loading amount of $\mathrm{CH}_{4}$ and the sequestration amount of $\mathrm{CO}_{2}$ in the nanochannels of the shale at different $\mathrm{CO}_{2}$ injection pressures. With the increase of $\mathrm{CO}_{2}$ injection pressure, the loading amount of $\mathrm{CH}_{4}$ in the shale decreases monotonically except for the case of $100 \AA$, and the sequestration amount of $\mathrm{CO}_{2}$ goes up steadily, which means the $\mathrm{CH}_{4}$ adsorbed in the shale nanochannel is displaced by $\mathrm{CO}_{2}$ and it is sequestrated simultaneously in the shale nanochannels. The reason for this phenomenon is that the shale nanochannel has stronger affinity to $\mathrm{CO}_{2}$ than to $\mathrm{CH}_{4}$, and shows selective adsorption for $\mathrm{CO}_{2}$. As a result, the $\mathrm{CH}_{4}$ molecules adsorbed in the nanochannel surfaces of shales are displaced by $\mathrm{CO}_{2}$ molecules, and the $\mathrm{CH}_{4}$ molecules are pushed back to the bulk phase finally.

A peak is observed in the case of the basal spacing $100 \AA$ in Figure $3 \mathrm{a}$. At low $\mathrm{CO}_{2}$ injection pressure, the adsorbed $\mathrm{CO}_{2}$ molecules induced the enhancement of $\mathrm{CH}_{4}$ adsorption compared with the pure $\mathrm{CH}_{4}$ adsorption; while at high $\mathrm{CO}_{2}$ injection pressure, the displacement of $\mathrm{CH}_{4}$ by $\mathrm{CO}_{2}$ is pronounced. This phenomenon was also observed in the 
work of Kowalczyk et al(Kowalczyk et al., 2012). At low $\mathrm{CO}_{2}$ injection pressure, some additional $\mathrm{CH}_{4}$ molecules are pumped from the bulk mixture gas into the shale. The adsorbed $\mathrm{CO}_{2}$ molecules can be acted as a part of the external field that overall enhances the solid-fluid interactions with bulk $\mathrm{CH}_{4}$ molecules(Kowalczyk et al., 2012), which leads to the slight increase of adsorption amount of $\mathrm{CH}_{4}$.

It is noted that the basal spacing of the shale model, i.e. the pore size, is crucial to the displacement amount of $\mathrm{CH}_{4}$ and the sequestration of $\mathrm{CO}_{2}$ in shales. For further explanation, Figure $3 \mathrm{c}$ and $3 \mathrm{~d}$ show the displacement amount of $\mathrm{CH}_{4}$ and the sequestration amount of $\mathrm{CO}_{2}$ at the $\mathrm{CO}_{2}$ injection pressure of $80 \mathrm{MPa}$. The shale gas reservoirs often contain the free gas in relatively large pores and the adsorbed gas associated with organic matters and inorganic minerals. Both free and adsorbed gases are important for application of exploitation of shale gas. Hence, the absolute amount is more significant than the excess amount for estimating the storage of shale gas reservoirs. With the increase in the basal spacing of the shale model, the displacement amount of $\mathrm{CH}_{4}$ and the sequestration amount of $\mathrm{CO}_{2}$ are increased sharply (see Figure $3 \mathrm{c}$ and $3 \mathrm{~d}$ ). In fact, the increase of the basal spacing in the shale model will result in the enhancement of the pore volume. As a result, the absolute amount of $\mathrm{CH}_{4}$ and $\mathrm{CO}_{2}$ adsorbed in relatively large pores will be increased significantly. When $\mathrm{CH}_{4}$ is displaced by $\mathrm{CO}_{2}$ at the $\mathrm{CO}_{2}$ injection pressure of $80 \mathrm{MPa}$, the displacement amount of $\mathrm{CH}_{4}$ and the sequestration amount of $\mathrm{CO}_{2}$ in relatively large pores exceed that in relatively small pores obviously (see Figure 3c and 3d).

It is found from the inset of Figure 3c that the percentage of displacement is inversely proportional to the basal spacing of shale model (i.e. pore size). The reason could be that 
the enlargement of basal spacing reduces the selectivity of the shale for $\mathrm{CO}_{2}$ over $\mathrm{CH}_{4}$. That is to say, the affinity of the inner surface to $\mathrm{CO}_{2}$ in relatively small pores is stronger than that in relatively large pores. So, as the basal spacing of shale model increases gradually, the percentage of displacement goes down slightly. However, the displacement amount of $\mathrm{CH}_{4}$ is more important than the percentage of displacement for the exploitation of shale gas.

To get an insight into the microscopic behavior of $\mathrm{CH}_{4}$ displaced by $\mathrm{CO}_{2}$ in shale, Figure $4 \mathrm{a}-4 \mathrm{~d}$ show microscopic snapshots of the binary $\mathrm{CO}_{2}-\mathrm{CH}_{4}$ mixtures adsorbed in the nanochannels of shales at the $\mathrm{CO}_{2}$ injection pressure of $0,30,60,90 \mathrm{MPa}$, respectively, in which the $\mathrm{CH}_{4}$ partial pressure of $15 \mathrm{MPa}$ and $\mathrm{T}=310 \mathrm{~K}$ are fixed, and the basal spacing of the shale model is $25 \AA$. For comparison, Figure $4 \mathrm{e}$ shows the loading amount of $\mathrm{CH}_{4}$ and the sequestration amount of $\mathrm{CO}_{2}$ in the shales at different $\mathrm{CO}_{2}$ injection pressures. At the $\mathrm{CO}_{2}$ injection pressure of $0 \mathrm{MPa}$ (i.e. the initial state), the nanochannels are fully filled with $\mathrm{CH}_{4}$ molecules (Figure 4a). As $\mathrm{CO}_{2}$ is injected into the shale, a certain amount of $\mathrm{CO}_{2}$ is also adsorbed and a part of $\mathrm{CH}_{4}$ molecules are driven out from the nanochannels (Figure 4b-4d). The dynamic process is also presented in Supporting Information Video.

\subsection{The Displacement of Shale Gas by Carbon Dioxide at Different Geological Depths.}

In this section, the influence of the geological depths on the displacement of $\mathrm{CH}_{4}$ by $\mathrm{CO}_{2}$ was studied. The T/P conditions corresponding to the specific geological depth were listed in Table 2. Based on the fact that a large proportion of the pores within the gas shale matrix is nanosized, we take into account not only the micropores (17 $\AA$ ) but also the mesopores $(50 \AA)$. The displacement of $\mathrm{CH}_{4}$ by $\mathrm{CO}_{2}$ in micropores $(17 \AA)$ was investigated first (see Figure 5). Figure5a shows the relationship between the loading amount of $\mathrm{CH}_{4}$ in 
the shale and the $\mathrm{CO}_{2}$ injection pressure at different geological depths. It is found that the geological depth plays a key role in the displacement of $\mathrm{CH}_{4}$ by $\mathrm{CO}_{2}$. At the $\mathrm{CO}_{2}$ injection pressure of $0 \mathrm{MPa}$ (i.e. the initial state), the loading amounts of $\mathrm{CH}_{4}$ in the shales from 1 to $4 \mathrm{~km}$ are nearly close with a slight difference. When $\mathrm{CO}_{2}$ gas is injected into the shale, the loading of $\mathrm{CH}_{4}$ in the shale goes down gradually. If the $\mathrm{CO}_{2}$ injection pressure is kept the same, the loading reduction of $\mathrm{CH}_{4}$ in the shales at the geological depth of $1 \mathrm{~km}$ is maximal in the four cases. If we only considered the displacement amount of $\mathrm{CH}_{4}$, the geological depth of $1 \mathrm{~km}$ is the best choice in all the cases studied here. In addition, the sequestration amount of $\mathrm{CO}_{2}$ is as important as the displacement of $\mathrm{CH}_{4}$. Figure $5 \mathrm{~b}$ shows the sequestration amount of $\mathrm{CO}_{2}$ versus the $\mathrm{CO}_{2}$ injection pressure at the geological depths from 1 to $4 \mathrm{~km}$. As expected, the sequestration amount of $\mathrm{CO}_{2}$ increases with the $\mathrm{CO}_{2}$ injection pressure (see Figure 5b), while it decreases with the increase of geological depth at a fixed $\mathrm{CO}_{2}$ injection pressure (see Figure $5 \mathrm{~d}$ ). That is to say, the sequestration of $\mathrm{CO}_{2}$ is maximum at geological depth of $1 \mathrm{~km}$ in all the four cases studied (Figure 5d). Actually, the effect of $\mathrm{CO}_{2}$ injection pressure on the displacement of shale gas is significant. The higher the $\mathrm{CO}_{2}$ partial pressure, the larger is the displacement amount of $\mathrm{CH}_{4}$ and the sequestration amount of $\mathrm{CO}_{2}$. Interestingly, at the geological depth of $1 \mathrm{~km}$, the percentage of displacement at the $\mathrm{CO}_{2}$ injection pressure of $80 \mathrm{MPa}$ is also the maximum among the four cases studied (see Figure 5c).Consequently, it is concluded that by considering the displacement of $\mathrm{CH}_{4}$, the sequestration of $\mathrm{CO}_{2}$ and the percentage of displacement in the shales, we found that it is at the geological depth of $1 \mathrm{~km}$ that the displacement efficiency of $\mathrm{CH}_{4}$ in shales by $\mathrm{CO}_{2}$ is the highest. 
We also studied mesopores by adjusting the basal spacing of shale model from 17 to $50 \AA$ (see Figure 6), and a similar phenomenon with the microporous shales appears. Finally, we propose that the optimum operating condition that the $\mathrm{CO}_{2}$ gas displaces the $\mathrm{CH}_{4}$ gas in the shales, is under the geological depth of $1 \mathrm{~km}$ no matter what the shales are microporous or mesoporous, which would provide significant information and reference for displacement exploitation of shale gas and sequestration of $\mathrm{CO}_{2}$.

\section{Conclusion}

We have used GCMC simulation to investigate the displacement of shale gas by $\mathrm{CO}_{2}$ and the sequestration of $\mathrm{CO}_{2}$ simultaneously in a modeled shale matrix at different geological depths up to $4 \mathrm{~km}$. the shale model was constructed by organic-inorganic composites, and the rationality of the shale model was evaluated by fitting the experiment data. The results indicate that the $\mathrm{CO}_{2}$ molecules can displace the shale gas adsorbed in the shales efficiently and the $\mathrm{CO}_{2}$ is sequestrated into the shales simultaneously. It is found that the pore size, i.e. basal spacing, plays an important role in the displacement of $\mathrm{CH}_{4}$ by $\mathrm{CO}_{2}$. Interestingly, both the displacement amount of $\mathrm{CH}_{4}$ and the sequestration amount of $\mathrm{CO}_{2}$ increase with the pore size of the shales. However, with the increase of the geological depth, all the displacement amount of $\mathrm{CH}_{4}$, the percentage of displacement and the sequestration amount of $\mathrm{CO}_{2}$ decrease obviously. Accordingly, we suggest that the geological depth of 1 $\mathrm{km}$ is the optimum operating condition for the displacement of $\mathrm{CH}_{4}$ by $\mathrm{CO}_{2}$ in the shales discussed here. It is expected that this work would provide microscopic fundamentals and significant reference for displacement exploitation of shale gas and sequestration of $\mathrm{CO}_{2}$. 


\section{Acknowledgement}

This work is supported by NSF of China (No. 91334203, 20274011) and Excellent

Talent Plan of BUCT. We are greatly thankful to Dr. Xu Jin and Xiaoqi Wang from

PetroChina and Prof. Wenchuan Wang from BUCT for helpful discussion and significant

revision.

\section{REFERENCES}

Arora, V., Cai, Y., 2014. U.S. natural gas exports and their global impacts. Applied Energy 120, 95-103.

Ashmoore, O., Evensen, D., Clarke, C., Krakower, J., Simon, J., 2016. Regional newspaper coverage of shale gas development across Ohio, New York, and Pennsylvania: Similarities, differences, and lessons. Energy Res. Soc. Sci. 11, 119-132.

Cao, D., Zhang, X., Chen, J., Wang, W., Yun, J., 2003. Optimization of Single-Walled Carbon Nanotube Arrays for Methane Storage at Room Temperature. J. Phys. Chem. B 107, 13286-292.

Chen, H., Carter, K.E., 2016. Water usage for natural gas production through hydraulic fracturing in the United States from 2008 to 2014. J Environ Manage 170, 152-159.

Clark, C., Burnham, A., Harto, C., Horner, R., 2012. Hydraulic fracturing and shale gas production: Technology, impacts, and policy. Argonne National Laboratory. Sep. 10.

Clarkson, C., Haghshenas, B., Ghanizadeh, A., Qanbari, F., Williams-Kovacs, J., Riazi, N., Debuhr, C., Deglint, H., 2016. Nanopores to Megafractures: Current Challenges and Methods for Shale Gas Reservoir and Hydraulic Fracture Characterization. J. Natural Gas Sci. Eng. 31, 612-657.

Clarkson, C.R., Solano, N., Bustin, R.M., Bustin, A.M.M., Chalmers, G.R.L., He, L., Melnichenko, Y.B., Radliński, A.P., Blach, T.P., 2013. Pore structure characterization of North American shale gas reservoirs using USANS/SANS, gas adsorption, and mercury intrusion. Fuel 103, 606-616.

Connor, J., Molofsky, L., Richardson, S., Bianchi-Mosquera, G., 2015. Environmental Issues and Answers Related to Shale Gas Development, SPE Latin American and Caribbean Health, Safety, Environment and Sustainability Conference. July 7-8.

Cui, X., Bustin, A.M.M., Bustin, R.M., 2009. Measurements of gas permeability and diffusivity of tight reservoir rocks: different approaches and their applications. Geofluids 9, 208-223.

Cygan, R.T., Liang, J.-J., Kalinichev, A.G., 2004. Molecular models of hydroxide, 
oxyhydroxide, and clay phases and the development of a general force field. J. Phys. Chem. B 108, 1255-1266.

Gasparik, M., Ghanizadeh, A., Bertier, P., Gensterblum, Y., Bouw, S., Krooss, B.M., 2012. High-Pressure Methane Sorption Isotherms of Black Shales from The Netherlands. Energy \& Fuels 26, 4995-5004.

Gupta, A., Chempath, S., Sanborn, M.J., Clark, L.A., Snurr, R.Q., 2003. Object-oriented programming paradigms for molecular modeling. Molecular Simulation 29, 29-46.

Howarth, R.W., Santoro, R., Ingraffea, A., 2011. Methane and the greenhouse-gas footprint of natural gas from shale formations. Climatic Change 106, 679-690.

Hu, X., Radosz, M., Cychosz, K.A., Thommes, M., 2011. CO2-filling capacity and selectivity of carbon nanopores: synthesis, texture, and pore-size distribution from quenched-solid density functional theory (QSDFT). Environ Sci Technol 45, 7068-7074.

Jorgensen, W.L., Maxwell, D.S., Tirado-Rives, J., 1996. Development and testing of the OPLS all-atom force field on conformational energetics and properties of organic liquids. J. Am. Chem. Soc. 118, 11225-11236.

Kowalczyk, P., Gauden, P.A., Terzyk, A.P., Furmaniak, S., Harris, P.J.F., 2012. Displacement of Methane by Coadsorbed Carbon Dioxide Is Facilitated In Narrow Carbon Nanopores. J. Phys. Chem. C 116, 13640-13649.

Krogulec, E., Sawicka, K., 2015. Groundwater protection in shale gas exploration areas-a Polish perspective. Episodes 38, 9-20.

Krupnick, A.J., Gordon, H.G., 2015. What Experts Say About the Environmental Risks of Shale Gas Development. Agricult. Resour. Econom. Review 44, 106-119.

Lan, J., Cao, D., Wang, W., 2010. High uptakes of methane in Li-doped 3D covalent organic frameworks. Langmuir 26, 220-226.

Liu, Y., Wilcox, J., 2013. Molecular simulation studies of $\mathrm{CO}_{2}$ adsorption by carbon model compounds for carbon capture and sequestration applications. Environ Sci Technol 47, 95-101.

Mayo, S.L., Olafson, B.D., Goddard, W.A., 1990. DREIDING: a generic force field for molecular simulations. J. Phys. Chem. 94, 8897-8909.

Pathak, M., Pawar, G., Huang, H., Deo, M.D., 2015. Carbon Dioxide Sequestration and Hydrocarbons Recovery in the Gas Rich Shales: An Insight from the Molecular Dynamics Simulations, Carbon Management Technology Conference. Nov. 17-19

Peng, X., Cheng, X., Cao, D., 2011. Computer simulations for the adsorption and separation of $\mathrm{CO} 2 / \mathrm{CH} 4 / \mathrm{H} 2 / \mathrm{N} 2$ gases by UMCM-1 and UMCM-2 metal organic frameworks. J. Mater. Chem. 21, 11259.

Shaikh, F., Ji, Q., 2016. Forecasting natural gas demand in China: Logistic modelling analysis. Int. J. Electr. Power Energy Systems 77, 25-32.

Shi, J.Q., Durucan, S., 2003. A bidisperse pore diffusion model for methane displacement 
desorption in coal by $\mathrm{CO}_{2}$ injection. Fuel 82, 1219-1229.

Talu, O., Myers, A.L., 2001. Molecular simulation of adsorption: Gibbs dividing surface and comparison with experiment. AIChE J. 47, 1160-1168.

Tan, J., Horsfield, B., Fink, R., Krooss, B., Schulz, H.-M., Rybacki, E., Zhang, J., Boreham, C.J., van Graas, G., Tocher, B.A., 2014. Shale Gas Potential of the Major Marine Shale Formations in the Upper Yangtze Platform, South China, Part III: Mineralogical, Lithofacial, Petrophysical, and Rock Mechanical Properties. Energy \& Fuels 28, 2322-2342.

Titiloye, J.O., Skipper, N.T., 2005. Monte Carlo and molecular dynamics simulations of methane in potassium montmorillonite clay hydrates at elevated pressures and temperatures. J. Colloid Int. Sci. 282, 422-427.

Wang, J., Jiang, H., Zhou, Q., Wu, J., Qin, S., 2016. China's natural gas production and consumption analysis based on the multicycle Hubbert model and rolling grey model. Renewable and Sustainable Energy Reviews 53, 1149-1167.

Wang, J., Wang, Y., Fan, J., Liu, C., Xue, P., 2015a. Experimental study on coal-bed methane displacement by carbon dioxide injection. Sci. Technol. Rev. 17, 022.

Wang, L., Wang, Z., Li, K., Chen, H., 2015b. Comparison of enhanced coalbed methane recovery by pure $\mathrm{N} 2$ and $\mathrm{CO} 2$ injection: Experimental observations and numerical simulation. J. Natural Gas Sci. Eng. 23, 363-372.

Wu, H., Chen, J., Liu, H., 2015. Molecular Dynamics Simulations about Adsorption and Displacement of Methane in Carbon Nanochannels. J. Phys. Chem. C 119, 13652-13657.

Youinou, G.J., 2016. Powering sustainable low-carbon economies: Some facts and figures. Renew. Sustain. Energy Rev. 53, 1626-1633.

Yu, H., Yuan, J., Guo, W., Cheng, J., Hu, Q., 2008. A preliminary laboratory experiment on coalbed methane displacement with carbon dioxide injection. Int. J. Coal Geology 73, 156-166.

Yuan, Q., Zhu, X., Lin, K., Zhao, Y.-P., 2015. Molecular dynamics simulations of the enhanced recovery of confined methane with carbon dioxide. Phys. Chem. Chem. Phys. 17, 31887-31893.

Zeng, F., Huang, W.B., Liu, M., Lu, S.F., Yu, L., 2014. A Study on Quantitative Characterization of Adsorption Capacity of Shale, Adv. Mater. Res. pp. 20-25.

Zhai, Z., Wang, X., Jin, X., Sun, L., Li, J., Cao, D., 2014. Adsorption and Diffusion of Shale Gas Reservoirs in Modeled Clay Minerals at Different Geological Depths. Energy \& Fuels 28, 7467-7473.

Zhang, T., Ellis, G.S., Ruppel, S.C., Milliken, K., Yang, R., 2012. Effect of organic-matter type and thermal maturity on methane adsorption in shale-gas systems. Org. Geochem. 47, $120-131$. 
Table 1.Force field parameters for adsorbates and adsorbents

\begin{tabular}{|c|c|c|c|c|}
\hline molecules & atoms & charge $[e]$ & $\boldsymbol{\sigma}[\AA]$ & $\varepsilon / \boldsymbol{k}_{B}[\boldsymbol{K}]$ \\
\hline Methane & $\mathrm{CH}_{4}$ & 0 & 3.73 & 148 \\
\hline \multirow{2}{*}{ Carbon Dioxide } & $\mathrm{C}$ & 0.70 & 2.80 & 27 \\
\hline & $\mathrm{O}$ & -0.35 & 3.05 & 79 \\
\hline \multirow{6}{*}{ Inorganic } & $\mathrm{H}$ & 0.424 & & \\
\hline & O (octahedral) & -1.424 & 3.55 & 78.26 \\
\hline & $\mathrm{O}$ (tetrahedral) & -0.8 & 3.55 & 78.26 \\
\hline & O (apical) & -1.0 & 3.55 & 78.26 \\
\hline & $\mathrm{Al}$ & 3.0 & 4.79 & 0.0007 \\
\hline & $\mathrm{Si}$ & 1.2 & 3.71 & 0.0009 \\
\hline \multirow{2}{*}{ Organic } & $\mathrm{C}$ & - & 3.47 & 47.9 \\
\hline & $\mathrm{H}$ & - & 2.85 & 7.7 \\
\hline
\end{tabular}

Table 2.Temperature and Pressure Conditions in Different Geological Depths

\begin{tabular}{cccc}
\hline case & depth & $\mathrm{T}$ & $\mathrm{P}$ \\
\hline Case 1 & $1 \mathrm{~km}$ & $310 \mathrm{~K}$ & $15 \mathrm{MPa}$ \\
Case 2 & $2 \mathrm{~km}$ & $340 \mathrm{~K}$ & $30 \mathrm{MPa}$ \\
Case 3 & $3 \mathrm{~km}$ & $370 \mathrm{~K}$ & $45 \mathrm{MPa}$ \\
Case 4 & $4 \mathrm{~km}$ & $400 \mathrm{~K}$ & $60 \mathrm{MPa}$ \\
\hline
\end{tabular}




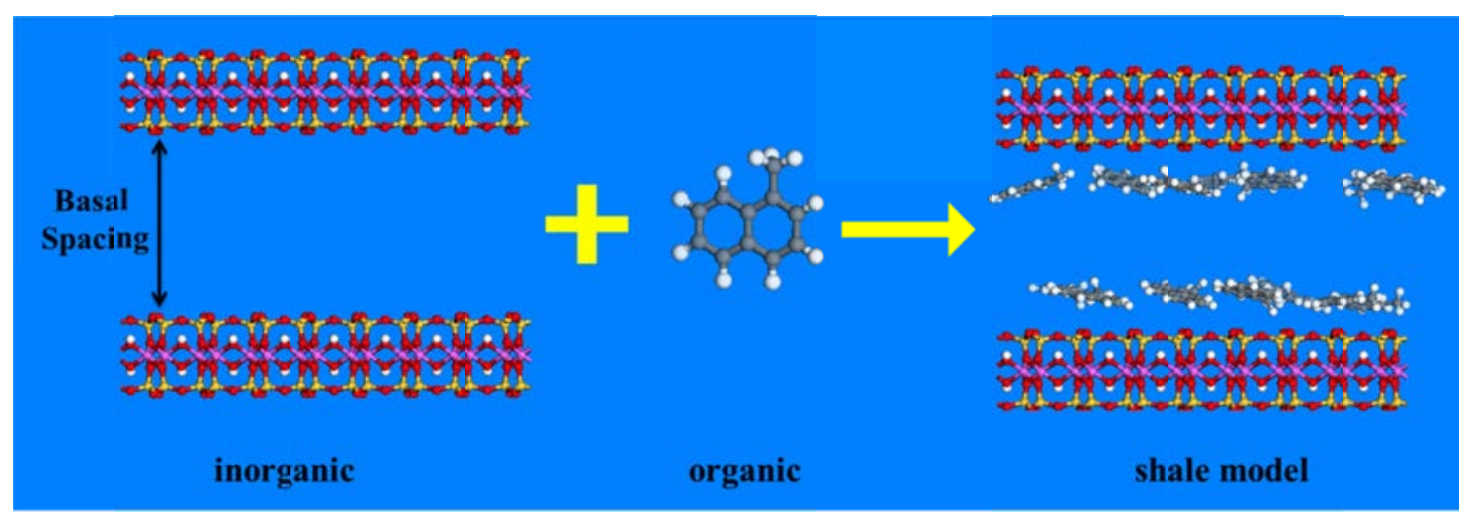

Figure 1. The scheme of modeled shale matrix. Color scheme: red, oxygen; yellow, silicon; pink, aluminum; white, hydrogen; and black, carbon.

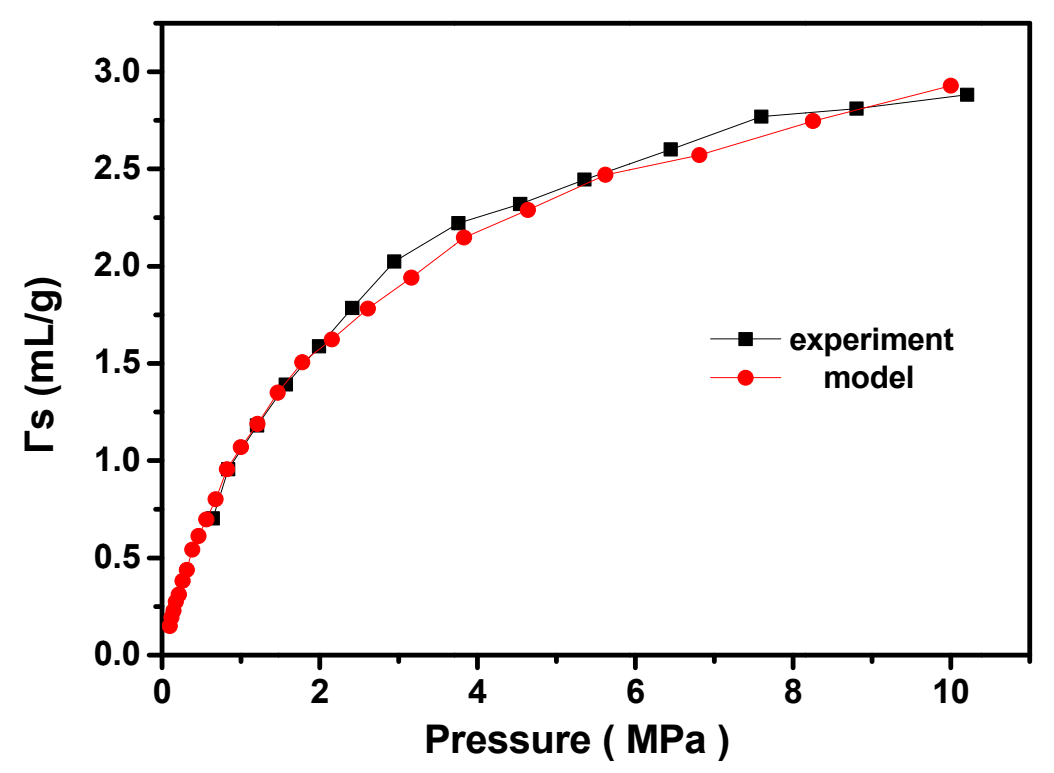

Figure 2. Adsorption isotherms of $\mathrm{CH}_{4}$ in the shales from experiment and simulation at $\mathrm{T}=363 \mathrm{~K}$. 
(a)

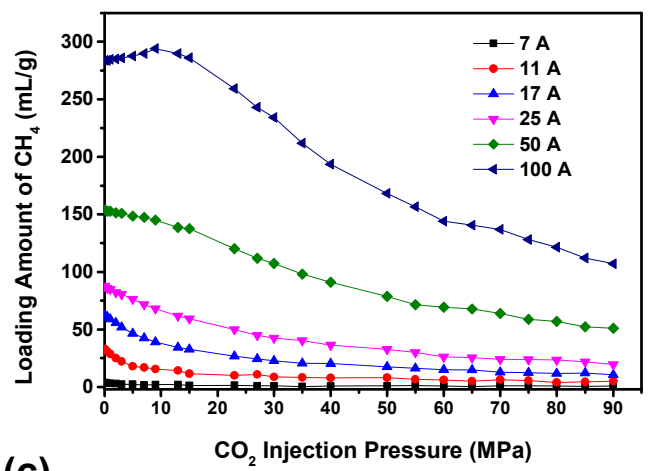

(c)

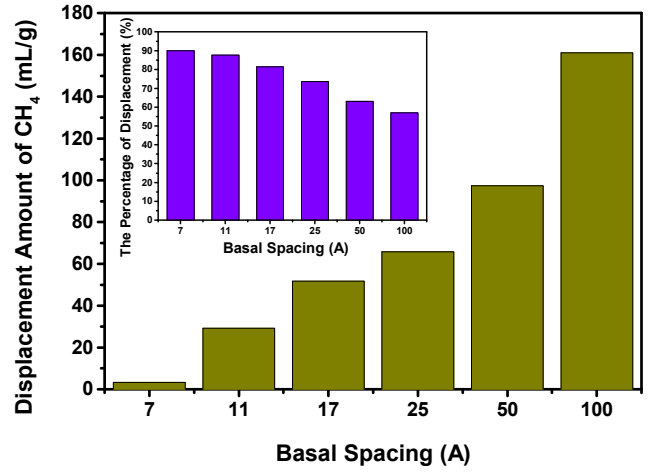

(b)

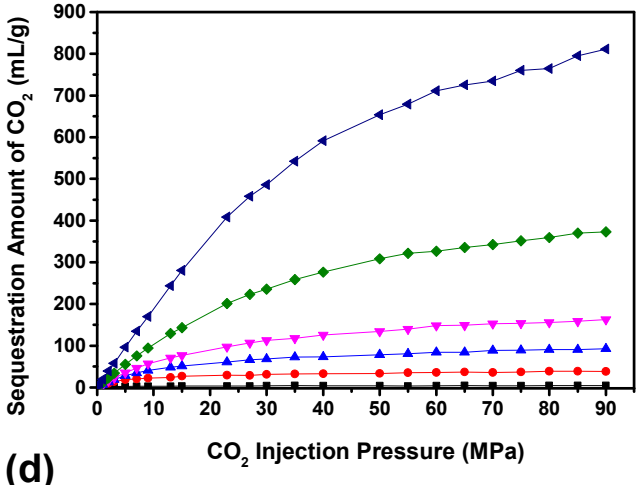

(d)

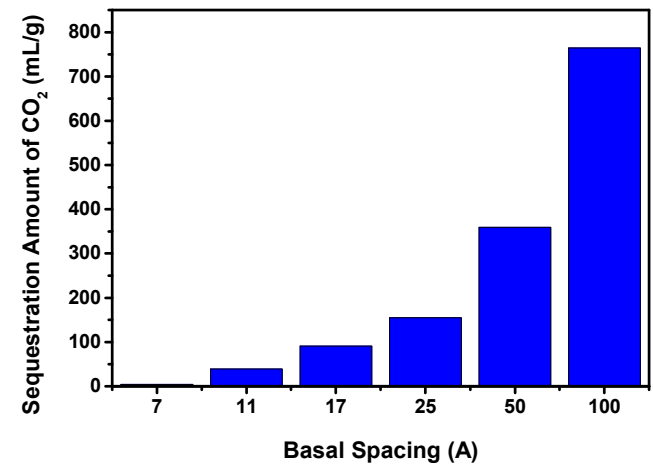

Figure 3. (a) The loading amount of $\mathrm{CH}_{4}$ and(b) the sequestration amount of $\mathrm{CO}_{2}$ in the modeled shales at different $\mathrm{CO}_{2}$ injection pressures and $\mathrm{T}=310 \mathrm{~K}$, where the partial pressure of $\mathrm{CH}_{4}$ is fixed at $15 \mathrm{MPa}$, corresponding to the pressure condition of shale gas at the geological depth of $1 \mathrm{~km}$, and the $\mathrm{CO}_{2}$ injection pressure is increased gradually from 0 to $90 \mathrm{MPa}$.(c) the displacement amount of $\mathrm{CH}_{4}$, and the inset of (c) is the percentage of displacement at the $\mathrm{CO}_{2}$ injection pressure of $80 \mathrm{MPa}$ and $\mathrm{T}=310 \mathrm{~K}$. (d) the sequestration amount of $\mathrm{CO}_{2}$. 
(a)

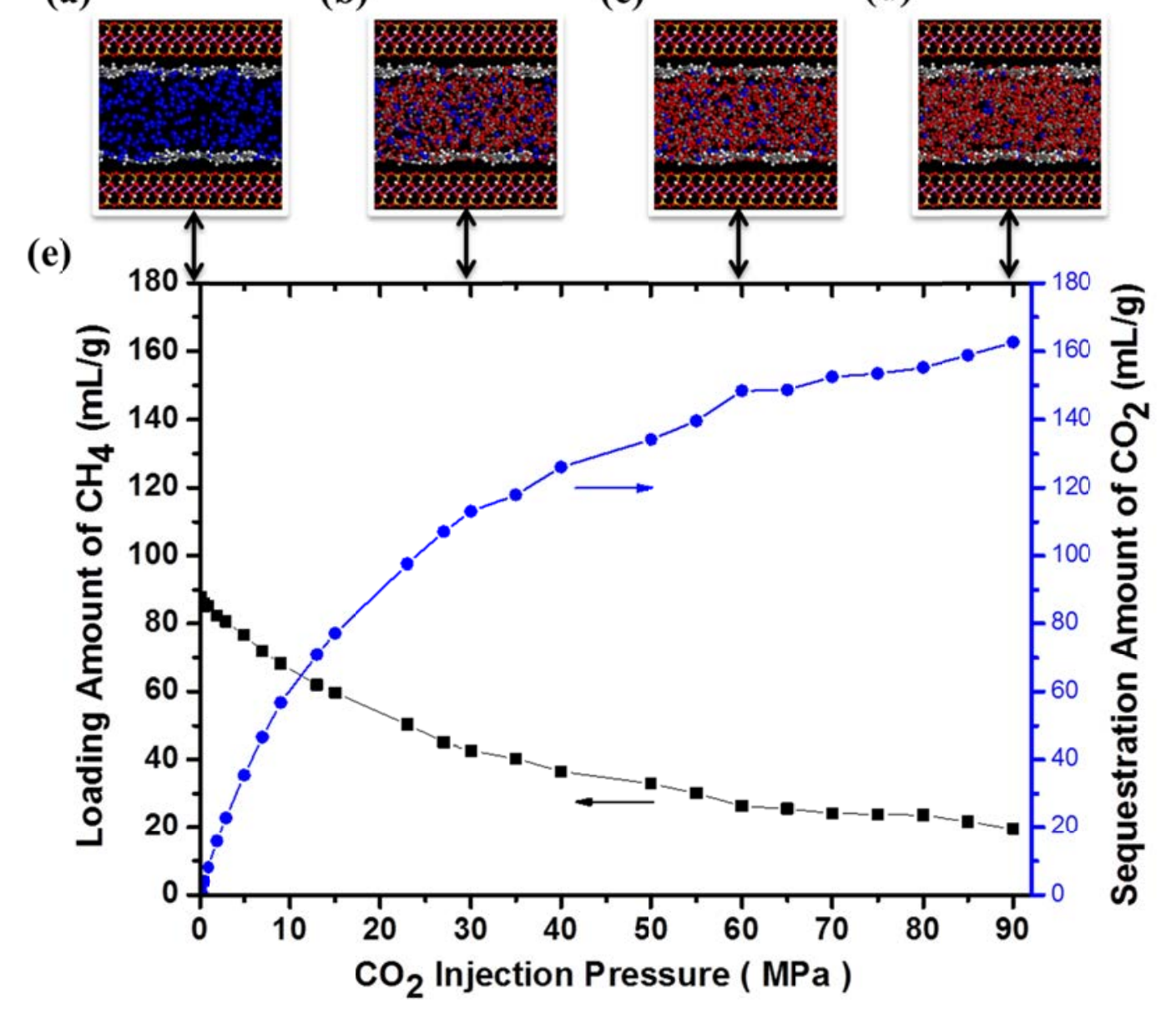

Figure 4. The snapshots of the binary $\mathrm{CO}_{2}-\mathrm{CH}_{4}$ mixtures adsorbed in the pore of shales at $\mathrm{T}=310 \mathrm{~K}$ and different $\mathrm{CO}_{2}$ injection pressures,(a) 0, (b) $30 \mathrm{MPa}$, (c)60 MPa, (d) $90 \mathrm{MPa}$. In all presented snapshots, the $\mathrm{CH}_{4}$ partial pressure of $15 \mathrm{MPa}$ is kept fixed in the bulk mixture. The basal spacing of shale model is set to be $25 \AA$ A. Color scheme: red, oxygen; black, carbon; blue, methane; yellow, silicon; pink, aluminum and white, hydrogen. (e) The loading of $\mathrm{CH}_{4}$ and the sequestration of $\mathrm{CO}_{2}$ at different $\mathrm{CO}_{2}$ injection pressures 
(a)

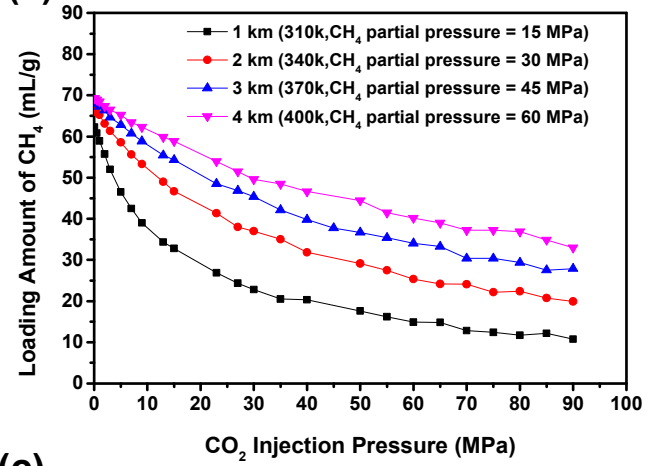

(c)

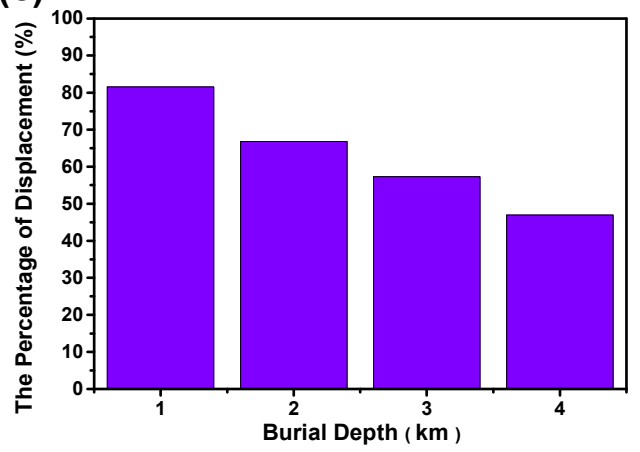

(b)

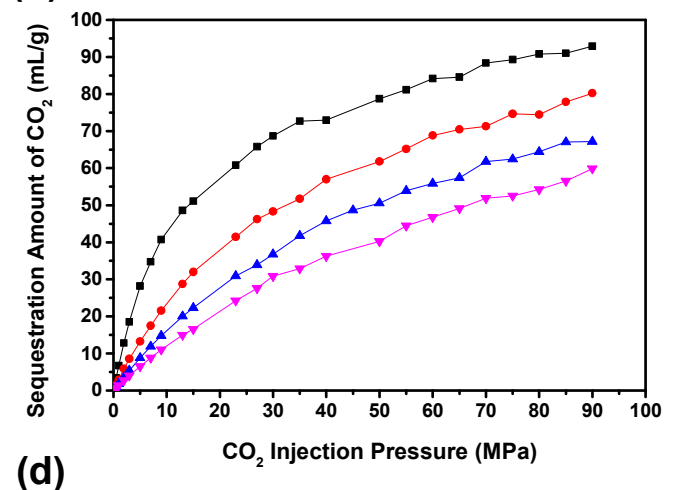

(d)

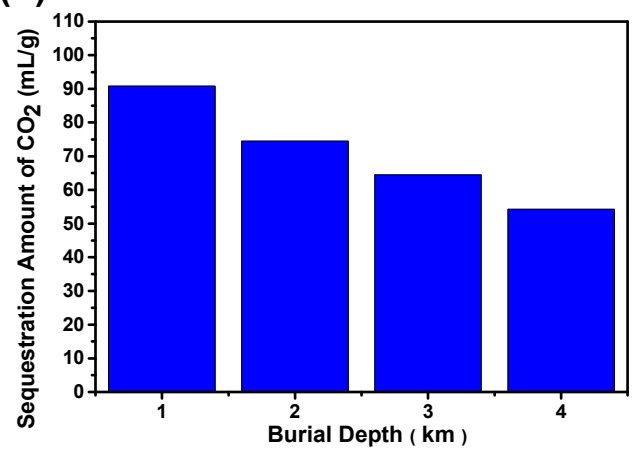

Figure 5.(a) The loading amount of $\mathrm{CH}_{4}$ and (b) the sequestration amount of $\mathrm{CO}_{2}$ in shales at different $\mathrm{CO}_{2}$ injection pressures and different geological depths. (c) The percentage of displacement and (d) the sequestration amount of $\mathrm{CO}_{2}$ in shale at the $\mathrm{CO}_{2}$ injection pressure of $80 \mathrm{MPa}$. The basal spacing of shale model is $17 \AA$ ( micropores ). 
(a)

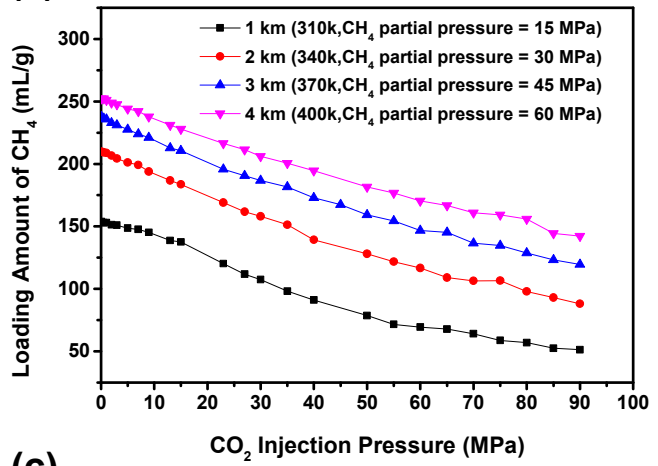

(c)

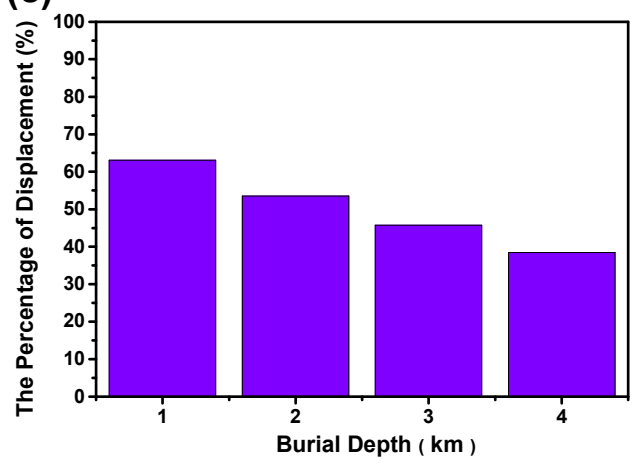

(b)

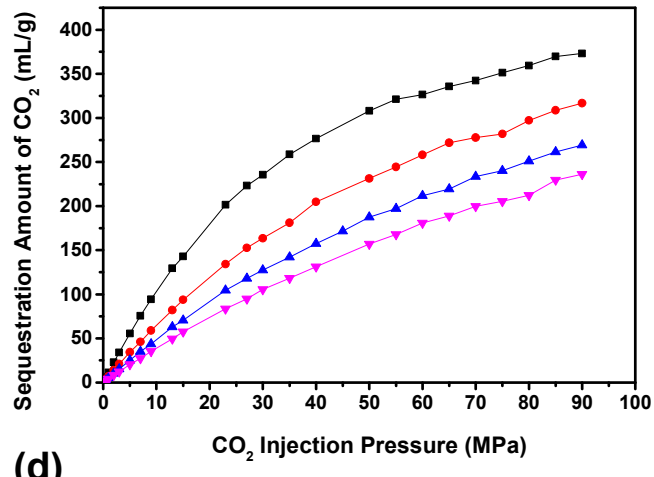

(d)

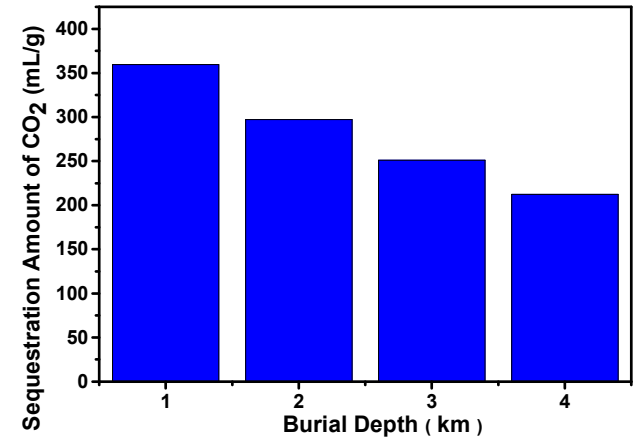

Figure 6.(a) The loading amount of $\mathrm{CH}_{4}$ and (b) the sequestration amount of $\mathrm{CO}_{2}$ in shales at different $\mathrm{CO}_{2}$ injection pressures and different geological depths. (c) The percentage of displacement and (d) the sequestration amount of $\mathrm{CO}_{2}$ in shale at the $\mathrm{CO}_{2}$ injection pressure of $80 \mathrm{MPa}$. The basal spacing of shale model is $50 \AA$ (mesopores). 
Table of Contents graphics

Molecular Simulation of Displacement of Shale Gas by Carbon Dioxide at Different Geological Depths Haibo Zhang and Dapeng Cao

\section{Graphical Abstract}

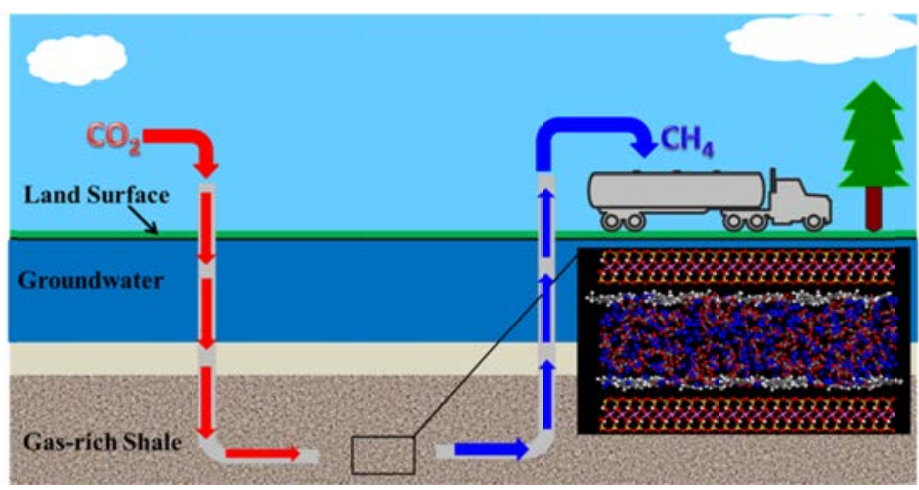

